Journal of Case Reports 2018;8(3):183-186

\title{
Intramural Hemorrhage of Cervical Ependymoma in Von Willebrand's Coagulopathy
}

\author{
Asma Mohammaddin ${ }^{1,2}$, Muhamad Almahayni ${ }^{3}$, Ahmed Alkhani1 ${ }^{1,2,4}$ \\ ${ }^{1}$ School of Medicine, Alfaisal University; ${ }^{2}$ Department of Neurosurgery, ${ }^{3}$ Department of Adult Hematology and Bone Marrow \\ Transplant, Oncology, King Faisal Specialist Hospital and Research Center; ${ }^{4}$ Department of Neurosurgery, King Abdulaziz Medical \\ city, National Guard Health Affairs, Riyadh, Saudi Arabia.
}

Corresponding Author:

Dr. Ahmed Alkhani

Email: alkhani@yahoo.com

This is an Open Access article distributed under the terms of the Creative Commons Attribution License (creativecommons.org/ licenses/by/3.0).

Received : December 16, 2017

Accepted : June 5,2018

Published : July 30, 2018

\begin{abstract}
Background: Spinal cord tumors are rare. Majority originate in glial cells. Ependymoma are the most common intra-medullary tumors in adults. Intra-mural hemorrhage is a rare presentation. Coagulopathy may contribute to such a presentation. Case Report: A 38-year-old male, known to have mild bleeding disorder presented with a sudden-onset neck pain. Magnetic resonance images (MRI) of the spine demonstrated an intra-medullary mass extending from $\mathrm{C} 5-\mathrm{T} 1$ with a cystic component that has features of sub-acute hemorrhage like fluid-fluid level sign. The patient underwent C5-T1 laminectomy, midline myelotomy, and microscopic total resection of the spinal classical ependymoma with intra-mural hemorrhage. Hematological investigation suggested the diagnosis of low von Willebrand factor (VWF). Conclusion: This is a rare case of an intra-medullary ependymoma that presented with intra-mural hemorrhage.
\end{abstract}

Keywords: Brain Stem Neoplasms, Ependymoma, Magnetic Resonance Imaging, Neck Pain, von Willebrand Factor.

\section{Introduction}

Spinal intra-medullary tumors are rare glial neoplasms. Ependymoma account for $60-70 \%$ of all the intra-medullary tumors [1,2]. Typically, ependymomas appear on MRI as iso-intense lesions on T1-weighted images and as hyper-intense lesions on T2-weighted images. It is frequently associated with syrinx formation. Intra-mural hemorrhage in spinal ependymoma tumor is an exception. A single case of possible hemorrhagic changes was reported in a series of 25 cases [3]. We report the clinical presentation and radiological manifestations of intra-mural hemorrhage in a cervical intra-medullary ependymoma.

\section{Case Report}

A 38-year-old previously healthy male presented with a sudden onset neck pain associated with bilateral radicular pain extending from the neck down to the fifth digits with numbness sensation bilaterally, mimicking C8 radiculopathy. The patient denied any symptoms of motor weakness or sphincters control difficulties. He denied any history of trauma or recent illness. His condition remained constant for a couple of weeks. His past medical history was worrisome for his tendency for easy bruising and prolonged bleeding when he underwent tooth extraction 15 years ago. At that time, the bleeding required only local measures to control it. There was no history of any other significant bleeding episode. At that time, he was investigated and diagnosed as a case of mild von Willebrand disease (VWD) type I. He was just advised to be aware of his condition. His family history was significant for his father had an undiagnosed bleeding tendency, which manifested as easy bruising as well. 
On examination, the patient was not in any pain or distress, with mild tenderness of the lower part of the neck posteriorly. He had a full range of cervical movement. His neurological examination revealed a slightly decreased pin-prick sensation in the distribution of the $\mathrm{C} 8$ dermatomes bilaterally. The rest of his sensory examination was within normal limits. Muscle tone and power in both the upper and lower extremities were normal and equal bilaterally. Bilateral generalized exaggerated deep tendon reflexes in the lower extremities and bilateral extensor planter responses were noted. His neurological examination was otherwise unremarkable.

A cervical spine MRI study was obtained and revealed an enlargement of the spinal cord with intra-dural intra-medullary mass extending from C5-T1 vertebrae. The central area of mass showed cystic changes of fluid-fluid level, representing subacute hemorrhage. The mass around the cystic changes had an iso-intense signal on T1 weighted images. It did enhance after intravenous gadolinium injection [Fig.1]. Complete neuroaxis MRI including the brain and spinal cord revealed no abnormalities otherwise.

As a pre-operative workup, and despite the history of mild VWD type 1, his laboratory results did not confirm such a diagnosis. As depicted in Table 1, the VWF antigen (VWF:Ag), von Willebrand factor-Ristocetin cofactor activity (VWF:RCO) and factor VIII activity were all on the higher end of the normal range. Platelet function tests were within normal limits, including PFA100, platelet aggregation, platelet glycoprotein and platelet electron microscopic examination [Table 1]. The patient was prepared for surgery by transfusing platelet concentrate and tranexamic acid. Recombinant factor VII was put on stand-by during the operation but it was not used.

Thereafter, he was operated on for C5T1 bilateral cervical laminectomy, midline myelotomy, and microscopic total resection of
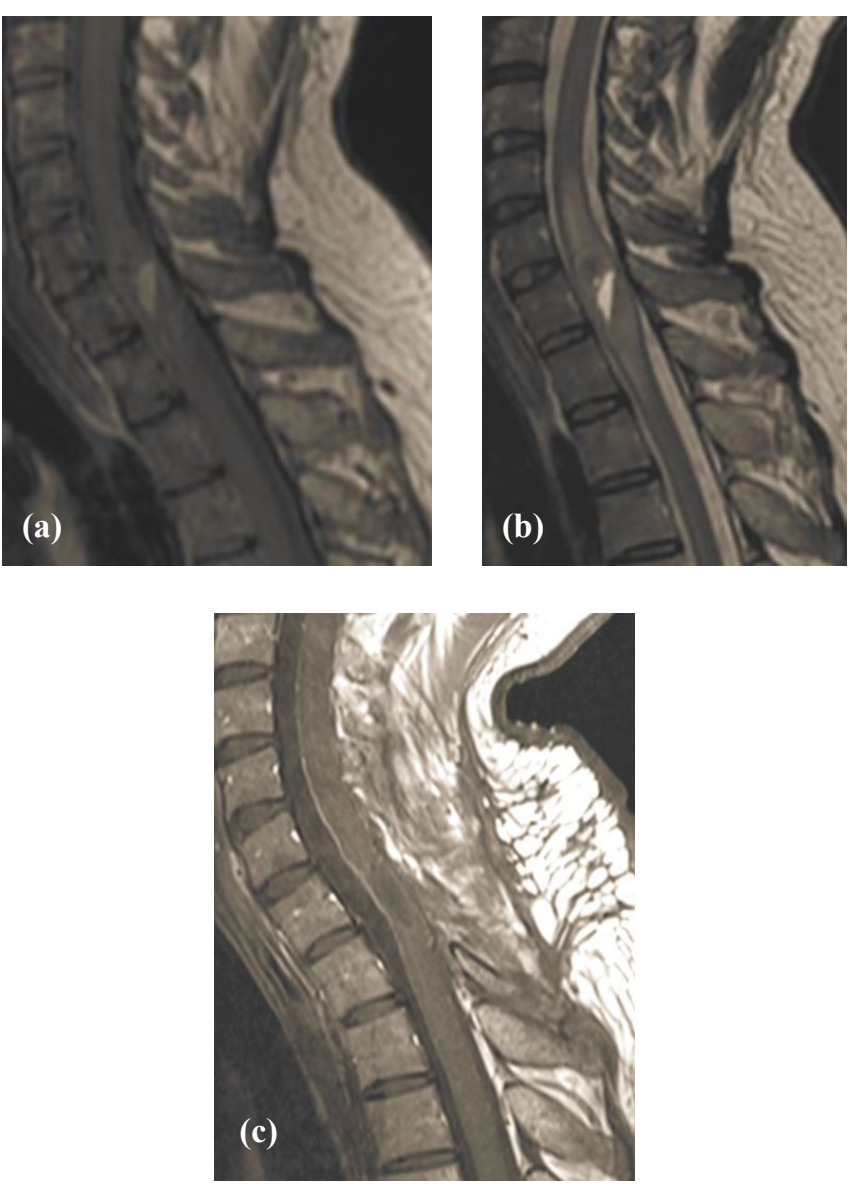

Fig.1(a): $T 1$ sagittal MRI of the cervical spine preoperatively. (b): T2 sagittal MRI of the cervical spine preoperatively. (c): Contrast-enhanced T1 sagittal MRI of the spine post-operatively.

the intra-medullary lesion under neurophysiology monitoring. The lesion was noted be brown to grey in color with intra-mural cavity that was filled with classical sub-acute hemorrhagic materials. The tumor was successfully resected with reasonable line of demarcation around it. Histopathological studies of the lesion revealed classical ependymoma (World Health Organization grade II).

Post-operatively, the patient had an uneventful recovery with mild dorsal column dysfunction that improved with time. On a couple of months post-operative follow-up visit, neurological symptoms had completely resolved. VWD work-up was repeated and it showed low VWF:Ag, low VWF:RCO activity, and low factor 
Table 1: Laboratory values.

\begin{tabular}{|l|l|l|l|}
\hline Tests & Results on admission & $\begin{array}{l}\text { Results 2 months post- } \\
\text { operatively }\end{array}$ & Reference Values \\
\hline Von Willebrand factor antigen (VWF:Ag) & $1.42 \mathrm{IU} / \mathrm{mL}$ & $0.52 \mathrm{IU} / \mathrm{mL}$ & $0.4-2.40 \mathrm{IU} / \mathrm{mL}$ \\
\hline $\begin{array}{l}\text { Von Willebrand factor-Risocetin cofactor } \\
\text { activity }\end{array}$ & $1.23 \mathrm{IU} / \mathrm{mL}$ & $0.43 \mathrm{IU} / \mathrm{mL}$ & $0.4-2.40 \mathrm{IU} / \mathrm{mL}$ \\
\hline Factor VIII activity & $>2.00 \mathrm{IU} / \mathrm{mL}$ & $0.44 \mathrm{IU} / \mathrm{mL}$ & $0.5-1.5 \mathrm{IU} / \mathrm{mL}$ \\
\hline Platelet count & $237 \times 10^{9} / \mathrm{L}$ & - & $150-450 \times 10^{9} / \mathrm{L}$ \\
\hline Prothrombin time & 13.7 seconds & - & $10-14 \mathrm{~seconds}$ \\
\hline Partial thromboplastin time & 30.4 seconds & - & $25-35$ seconds \\
\hline Platelet function assay (PFA-100) & 156 seconds & - & $<180$ seconds \\
\hline Platelet aggregation & $\begin{array}{l}\text { Normal response to all } \\
\text { agonists }\end{array}$ & - & N/A \\
\hline Platelet glycoproteins & Normal & - & N/A \\
\hline Platelet electron microscopy & Normal & - & N/A \\
\hline
\end{tabular}

VIII activity [Table 1]. These results are most fitting with a diagnosis of 'low VWF' rather than the previous diagnosis of 'mild VWD type 1'. A follow-up MRI at six months revealed no evidence of residual or recurrences of the lesion.

\section{Discussion}

We presented a case of intra-mural hemorrhage in cervical intra-medullary classical ependymoma in a patient with low VWD. Radiological features of classical ependymoma on MRI that aid in the identification of spinal ependymomas include, symmetrical spinal cord expansion, isointense signal intensity on non-enhanced, T1weighted images $[1,2,3]$. In case of mucinous component of the lesion, a hyper-intense signal on T1-weighted MRI can be seen [2]. Ependymomas classically show hyper-intense signals on T2-weighted MRI [3]. They also commonly contain well-circumscribed rim with low signal intensity on T2-weighted MRI. These changes are highly suggestive, but not pathognomonic, of ependymoma [4]. Lastly, syringo-hydromyelia and cystic changes (hypo-intense on T1 and bright hyper-intense on T2-weighted MRI) are commonly associated with intra-medullary tumors $[1,3]$. After the administration of intravenous gadolinium, the vast majority of ependymomas become enhancing with sharply demarcated borders from the adjacent spinal cord tissue [1]. The tumors showed intense uniform enhancement in $35 \%$ of the cases, whereas $65 \%$ had heterogeneous enhancement [3].

Radiological evidences of recent hemorrhages are quite unusual in ependymomas; only one reported case was found in our search of the literature [3]. The case was published as part of a review article in 1995 Fine et al. out of the 25 cases studied in the article. It was found to be hyper-intense on non-enhanced T1 weighted MR images and was presumed to be hemorrhagic for that reason. No additional information or images were available regarding the case [3]. Thus, we believe that this case report is the first documented case with intramural bleed available to date.

At the pre-operative laboratory work upon the day of his admission, the patient's VWF level was within normal ranges. However, the level may have been low at the time of the hemorrhage. Normal level at admission (two weeks post hemorrhage) can be contributed to the stress condition a wellrecognized phenomenon. Patients with only mild decrease in VWF level in isolation have had significant bleeding tendency. The low level of VWF in our patient can also reflect additional defects in the hemostatic pathway, including mild 
platelet defects. This is further supported by the fact that VWF levels are relatively easy to measure in the laboratory in comparison to platelet function and could give the false impression that low VWF level is the only responsible factor for the bleeding symptoms [5].

The British Committee for Standards in Hematology recommendations states that a diagnosis of VWD can only be made when VWF activity is $<0.30 \mathrm{IU} / \mathrm{mL}$ [6]. However, patients with an appropriate bleeding history and VWF activity between 0.3 and $0.5 \mathrm{IU} / \mathrm{mL}$ should be regarded as having a primary hemostatic bleeding disorder with reduced VWF as a risk factor, rather than VWD itself; these patients should be referred to as 'low VWF' [6]. Similarly, the patient in this case had a suitable bleeding history and his postoperative VWF activity was not below $0.30 \mathrm{IU} / \mathrm{mL}$ but within the aforementioned ranges [Table 2], and as such, he shall be diagnosed as having "low VWF".

\section{Conclusion}

Intramural hemorrhage is an exceptional and interesting presentation of spinal ependymomas. Hemorrhagic tendency may contribute to this phenomenon and needed to be ruled out.
Contributors: AM: manuscript writing, literature search; MA: manuscript editing, patient management; AA: critical inputs into the manuscript, patient management. AA will act as guarantor. All authors approved the final version of this manuscript.

Funding: None; Competing interests: None stated.

\section{References}

1. Koeller KK, Rosenblum RS, Morrison AL. Neoplasms of the spinal cord and filum terminale: Radiologicpathologic correlation. Radiographics. 2000;20:17211749.

2. Cho JCS, Miller A., Kettner NW. Cervical ependymoma in a male adolescent with neck and back pain. Journal of Manipulative and Physiological Therapeutics. 2009;32:695-700.

3. Fine MJ, Kricheff II, Freed D, Epstein FJ. Spinal cord ependymoma: MR imaging features. Radiology. 1995; 197:655-658.

4. Nemoto $\mathrm{Y}$, Inoue $\mathrm{Y}$, Tashiro T, Mochizuki K, Oda J, Kogame $\mathrm{S}$, et al. Intra-medullary spinal cord tumors: significance of associated hemorrhage at MR imaging. Radiology. 1992;182:793-796.

5. Millar CM, Riddell A, Tuddenham EG. Consideration of platelet function disorders in patients with reduced VWF levels. Haemophilia. 2008;14:1131-1132.

6. Laffan MA, Lester W, O'Donnell JS, Will A, Tait RC, Goodeve A, et al. The diagnosis and management of von willebrand disease: a united kingdom haemophilia centre doctors organization guideline approved by the british committee for standards in haematology. British Journal of Haematology. 2014;167:453-465. 